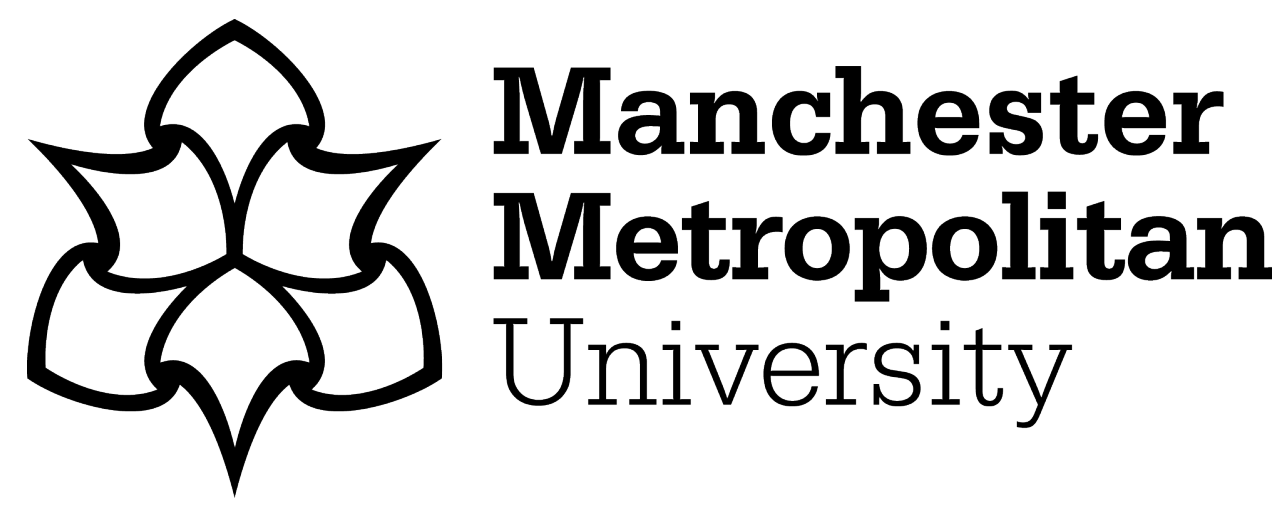

Papaioannou, V, Pietrosanti, S, Holderbaum, W, Becerra, VM and Mayer, R (2017) Analysis of energy usage for RTG cranes. Energy, 125. pp. 337-344. ISSN 0360-5442

Downloaded from: https://e-space.mmu.ac.uk/620872/

Publisher: Elsevier

DOI: https://doi.org/10.1016/j.energy.2017.02.122

Usage rights: Creative Commons: Attribution-Noncommercial-No Derivative Works 4.0

Please cite the published version 


\title{
Analysis of energy usage for RTG cranes
}

\author{
Vicky Papaioannou, Stefano Pietrosanti, William Holderbaum, Victor M. \\ Becerra, Rayner Mayer \\ University of Reading, Whiteknights Reading \\ RG6 6AY, UK
}

\begin{abstract}
The purpose of this paper is to study and analyse the energy that is used by the various motors of a crane of the Rubber Tyred Gantry type. For this reason a single Rubber Tyred Gantry (RTG) crane has been instrumented at port of Felixstowe and data has been collected during normal operation for eight days. This data has been analysed in terms of active and idle modes and also in terms of energy usage by the various motors. From this analysis it is possible to determine that on average about half of the energy consumed is potentially recoverable. It is also estimated that the recovery of this proportion of energy could lead to savings of 32,600 litres of fuel and 8,100 tonnes of $\mathrm{CO}_{2}$ per year at Port of Felixstowe.
\end{abstract}

Keywords: Energy analysis, RTG crane

\section{Introduction}

Container ports use a large amount of energy in moving thousands of containers a day. Each container that is lifted has to be lowered and this inertial energy can be recovered. In container cranes powered by electricity from the grid this recovered energy can be reused on the same crane, put back into the grid or used locally elsewhere in the port. In the case of the Rubber Tyred Gantry (RTG) cranes the energy is generally not recovered but is dissipated in dump resistors. When the RTG is diesel powered then it will typically use in excess of 120,000 litres of diesel fuel over the period of one year [21]. In large ports there may be up to 100 RTG cranes which

Email address: V.papaioannou@pgr.reading.ac.uk (Vicky Papaioannou) 
would consume million litres of diesel fuel resulting in thousands $\mathrm{kg} \mathrm{of} \mathrm{CO}_{2}$ emissions according to Port of Felixstowe. This amount of energy could be recovered locally on the crane in order to be used to raise the next container. In order to design a suitable and efficient energy storage system for an RTG crane, it is necessary to understand its energy usage patterns under typical operating cycles.

During the last decade research has been carried out in the direction of fitting various energy storage systems such as super capacitors[4], batteries[13] and flywheel systems to RTG cranes[5][9][12]. Results show through experimental testing that the fitting of energy storage systems on RTG cranes can reduce fuel consumption, diesel engine size and increase engine life [12]. Nevertheless, the area of analysing the energy usage by the different motors of an RTG crane has not been adequately investigated.

The University of Reading has collaborated with the Port of Felixstowe to collect and analyse data from both diesel and more recently electrically operated RTG cranes. Data has been collected from both standard tests and in service operation. The paper's contributions are the following:

- From the data derived from eight days of operation an overview is given of what part of the day the crane is actually working;

- How the energy is distributed between the different motors;

- An energy analysis concerning the various motors of the crane has been carried out;

- Finally a range of percentages of the total recoverable energy has been calculated depending on the workload of the specific day.

The paper's structure is as follows. Firstly, the RTG crane system is described. Then, a brief statistical analysis of the container weights and the container lifts is presented. The methodologies of data collection and data analysis are explained. Next, there is graphical and numerical presentation of the results regarding the time and energy distribution and the energy related to the various motors of the crane including the estimation of the losses and the potential recoverable energy. Finally the results and their analysis are briefly discussed before concluding. 


\section{Problem statement}

In large ports containers are transferred from tractor units to container rows using RTG cranes. In many cases each crane is powered by a diesel engine driving an alternator. Electricity is rectified and the DC network is used to distribute power to all the electric motors which drive the lift, trolley and motion of the RTG cranes. When containers are lowered the electric motors generate electricity and supply power back to the DC network. In the absence of an energy storage system this excess of energy is dumped into resistor banks. If suitable energy storage was in place this excess energy could be stored, recovered and used for the next lift. This could lead to significant energy savings since typically RTG cranes move hundreds of containers a day. The data obtained from a suitably instrumented RTG crane under typical operation can be used to determine how efficiently energy is used by the existing motors, and to study the options for improving the efficiency of the crane. Whereas the terminal operator is primarily concerned about cost, society concerns relate to environmental impact, both locally and globally. The reduction in $\mathrm{CO}_{2}$ emissions is of particular importance in limiting climate change as container ports are large energy users.

\section{Description of the RTG crane system}

Shipping ports are the gateway through which container are transferred from container ships to the land transport infrastructure (trains, lorries) and vice-versa. Containers are stored in stacks in the port while waiting to be transferred to a ship or to a lorry and the machine that is in charge of stacking containers is the RTG crane, which is designed to straddle over stacks. These cranes are usually equipped with four pairs of wheels that allow them to move around the terminal; this type of movement is known as "gantry movement".

Figure 1 shows an RTG crane in use at the Port of Felixstowe. From the simplified drawing in Figure 2 it shown the crane attaching safely to the container using the spreader; the spreader is connected to the crane by means of eight wires connected to a set of pulleys and a drum located in the trolley, where the operator's cabin is usually located.

- The trolley moves horizontally in a perpendicular direction with respect to the container length. This type of movement is known as "trolley movement"; 


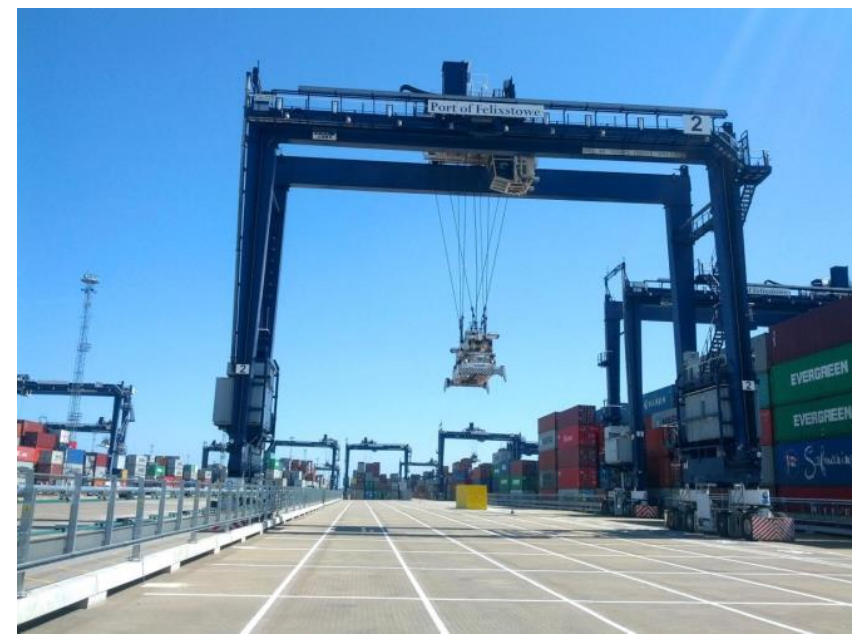

Figure 1: RTG crane in operation at the Port of Felixstowe

- The upwards and downwards movement of the spreader is accomplished by rotating of the main drum coupled to the hoist motor.This is called "hoist movement";

- The "gantry movement" is defined as the motion of the whole crane along the container stack using the four sets of rubber wheels.

All the actuators are electric motors and their ranking in terms of power consumption is, in descending order: the trolley motors, the gantry motors and the hoist motor the latter of which accounts for more than a quarter of the total energy consumption of the crane [15]. The electric energy that drives the motors is provided by either a diesel generator (in diesel powered RTG cranes) or the electric grid (in e-RTG cranes) [17].

The hoist, trolley and gantry motors are connected to a DC bus which is powered by the primary energy source through a rectifier, as shown in figure 3. The DC bus voltage decreases when the motors demand power (e.g. when lifting a container) and it increases when the motors regenerate power (e.g. when lowering a container). The regenerated energy is fed into the DC bus, allowing other motors to use part of the recovered energy, while all the surplus energy is then dumped into the brake resistors which activate when the DC bus voltage reaches a threshold. Most of the recoverable energy comes from the potential energy lost by the container after being lowered. 


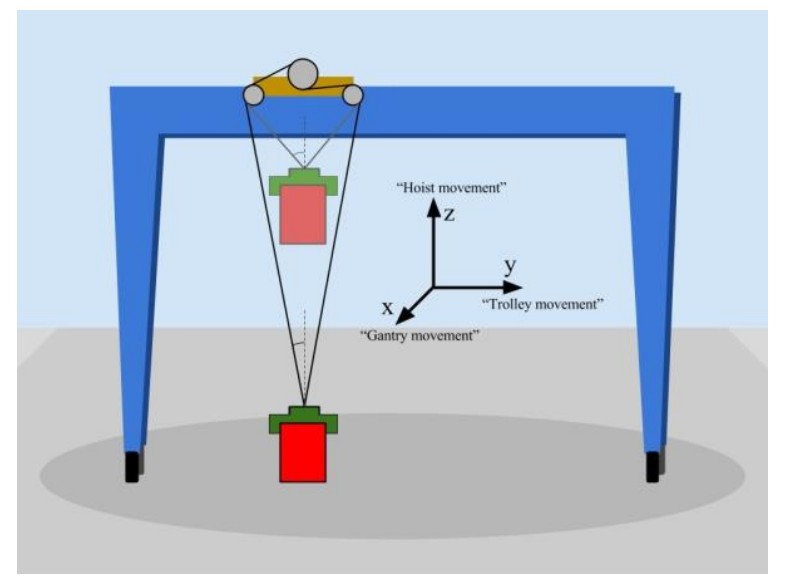

Figure 2: Drawing of an RTG crane and its movements along the three dimensions

Figure 3 shows the main electrical elements in a crane, including: a 3-phase power source which can be either a diesel genset or a connection to the power grid; a rectifier which feeds the DC bus; an electric motor and drive, which represents one or multiple motors that can act as power load or source; a dump resistor which dissipates excess energy (all the recovered energy, if no storage system is installed) and finally a Flywheel Energy Storage System (FESS), which is an example of storage technology that can be added to a crane and connected directly to the DC bus $[9,18,20]$.

\section{Methods}

\subsection{Data Collection}

A data logger has been used to collect data from the Programmable logic controller (PLC) which controls the movements of the RTG crane. A crane in the port of Felixstowe was monitored for eight typical working days in order to gather information on the day to day life of the crane. This data includes the energy that enters the rectifier of the DC link and the current and voltage of each of the crane motors. Additional information includes data that concern the state of the twist lock which indicated when the spreader is locked and unlocked. This data can be processed in order to determine the energy flows to and from each of the motors. Eight days of data has been collected in order to include both high activity and low activity days. Although the data covers an 8-day period, in order to accurately calculate the 


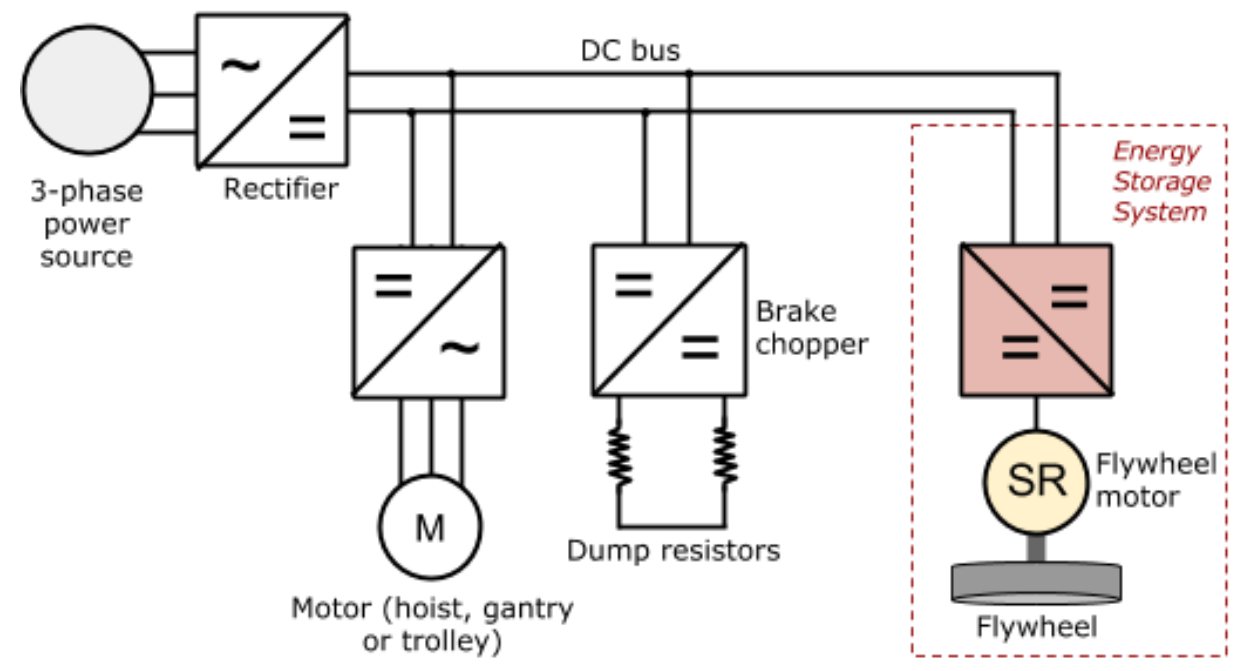

Figure 3: Diagram of the main electric elements of an RTG crane with the addition of an Energy Storage System [20]

energy usage and the potential for energy saving the analysis was performed only on days when the crane was actively used. The crane monitored is the most common model of RTG crane found at the Port of Felixstowe.

\subsection{Energy calculations}

Define $E_{r}, E_{h}, E_{g}$ as the rectifier energy, the hoist energy, and the gantry energy respectively . The electric energy that is consumed or generated by each motor is calculated by integrating the electric power over time using the Euler rule of integration (1).

$$
P=\frac{d E}{d t} \rightarrow \int_{t_{0}}^{t_{f}} d E=\int_{t_{0}}^{t_{f}} P d t \rightarrow E \simeq h \cdot \sum_{i=1}^{N-1} P_{i}
$$

where $E$ is the electric energy, $P$ is the electric power consumed or generated by the motor, $h$ is the sampling interval, $t_{0}$ is the initial time of the operation, and $t_{f}$ is the final time of the operation. As the motors are 3-phase, the expression for electric power is given by the following formula [16]:

$$
P={ }{ }_{-} 3 \cdot V_{R M S} \cdot I_{R M S}
$$

where $V_{R M S}$ is the RMS value of the voltage measured at terminals of the motor and $I_{R M S}$ is the RMS value of the AC phase current into the motor. 
Given that the majority of the energy is exchanged between the rectifier and the hoist and gantry motors, the rest of the energy consumption has been lumped into the variable $E_{l}$. This value mainly consists in the losses in the rectifier and DC bus, the trolley energy and all the rest of the energy that cannot be assigned to the main motors. It is calculated as follows:

$$
E_{l}=E_{r}-\left(E_{c}^{h}+E_{c}^{g}\right)
$$

where $E_{r}$ is the rectifier energy, $E_{c}^{h}$ is the consumed hoist energy and $E_{c}^{g}$ is the consumed gantry energy. Idle energy is defined as the amount of energy the crane consumes when it is in idle mode.

\subsection{Classification of days based on number of working hours}

The collected data over eight working days is classified into typical operation, low activity and very low activity days based on the number of operational hours as described in table 1 . This classification will be used later to discuss the results for each separate group of working days. Since the variety of amount of workload is represented in the collected data all working day scenarios are covered for the RTG cranes in PoF.

\begin{tabular}{|c|c|}
\hline $\begin{array}{l}\text { Number of working hours per } \\
\text { day }\end{array}$ & Classification of day \\
\hline $10-12$ & Typical operation \\
$6-7$ & Low activity \\
$1-2$ & Very low activity \\
\hline
\end{tabular}

Table 1: Classification of days

\section{Statistical analysis of activities}

As explained in Section 4.1, data has been collected from the crane PLC during operations. Among the information available, it was possible to also measure container weight, time interval between lifts, duration of lifts, energy demand and other crane activity parameters.

\subsection{Container weight}

The load weight was measured and the data collected was analysed in order to extract statistical information needed to determine the energy consumption of the crane. Figure 4 shows that the distribution over 4 days of 
the container weight is concentrated around two peaks, respectively 10 and 27 tons. This is due to the type of cargo being transported in the containers: some containers contain heavy and dense materials, others hold light goods or are empty. Table 2 shows the statistical values extracted from the measured weights.

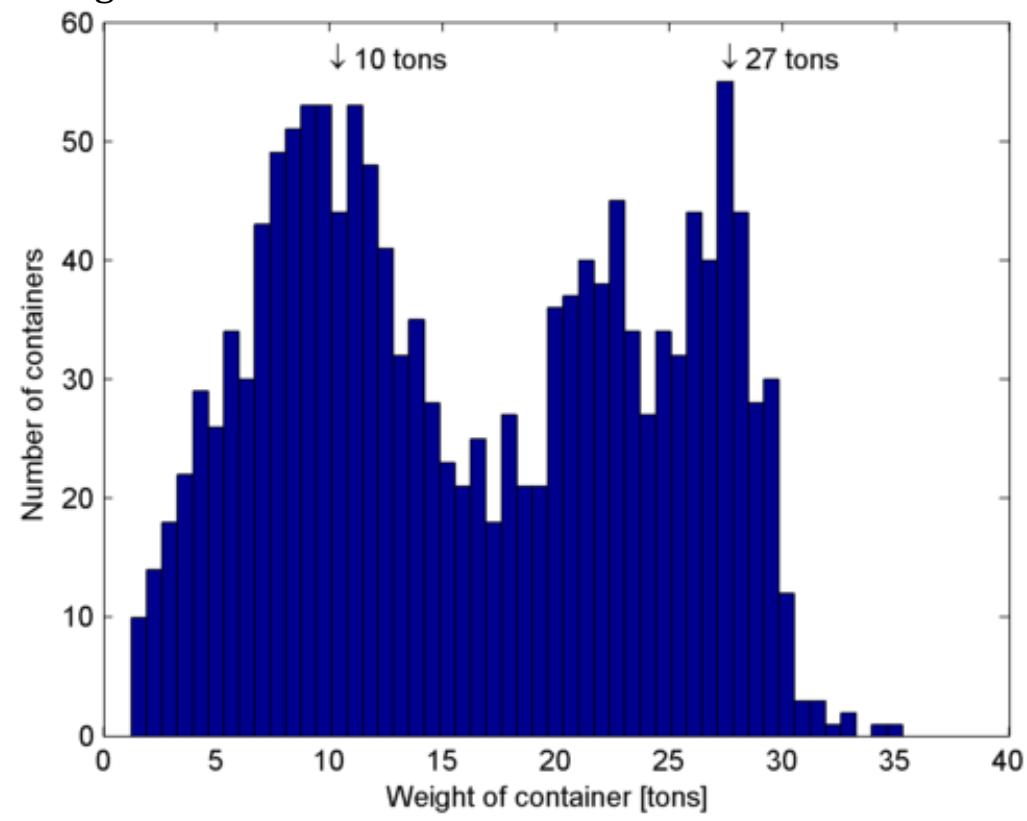

Figure 4: Histogram of the number of containers with the measured weight, data collected over a period of 4 days

\subsection{Interval between lifts}

Another key piece of information is the interval of time between lifts. The sizing of the power system associated with the crane is highly dependent on the amount of time that passes between situations of high power demand. Together with the measurement of the loads and the duration of lifts, this information can help assess the characteristics of the power demand. At comparable energy levels, short and frequent high power loads can be harder to manage compared to continuous low power loads [19]. For this reason, the intervals between a spreader lock and the subsequent relock (indicating that a container is being moved) has been measured and the results are presented in Figure 5 and Table 2.It is evident that most of the lifts occur less than a minute after the previous, and the distribution then decreases as the 
intervals increase. Intervals above 5 minutes have been discarded as they indicate that the crane has been idle and also they are few in number compared with the number of lift moves. An RTG crane usually enters idle mode after few minutes (depending on the model and energy savings equipment installed), so the analysis is limited to the short intervals in order to study the activity level of the crane. Furthermore, longer intervals are not relevant when assessing the energy consumption of a crane as they are not related to the activity of the crane (change of shifts, delays related to port logistics).

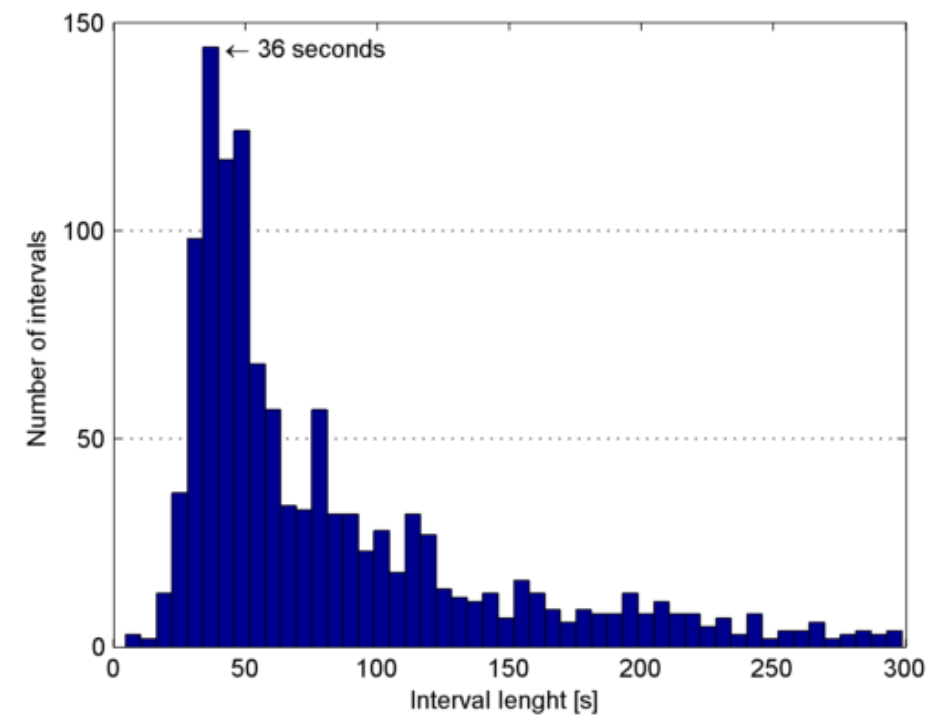

Figure 5: Histogram of the duration of the intervals between lifts, data collected over a period of 4 days

\subsection{Duration of container lift}

The primary energy source of the crane must provide high power during the duration of the container lift, as the hoist motor is the highest rated electrical machine in the crane. Masses of up to 52 tons (container plus spreader) are lifted for a duration of up to 65 seconds, with a peak power demand of up to $400 \mathrm{~kW}$. It then becomes very important to estimate the duration of the typical lifts, which depends on the height that the container needs to reach. Small and busy terminals will have containers placed in high stacks, while larger ports with low activity will prefer lower stacks; the height of the stacks will then influence the lift duration distribution. At the 
Port of Felixstowe, the measured durations are presented in Figure 6 and it is clear that the values are concentrated around 20 seconds.

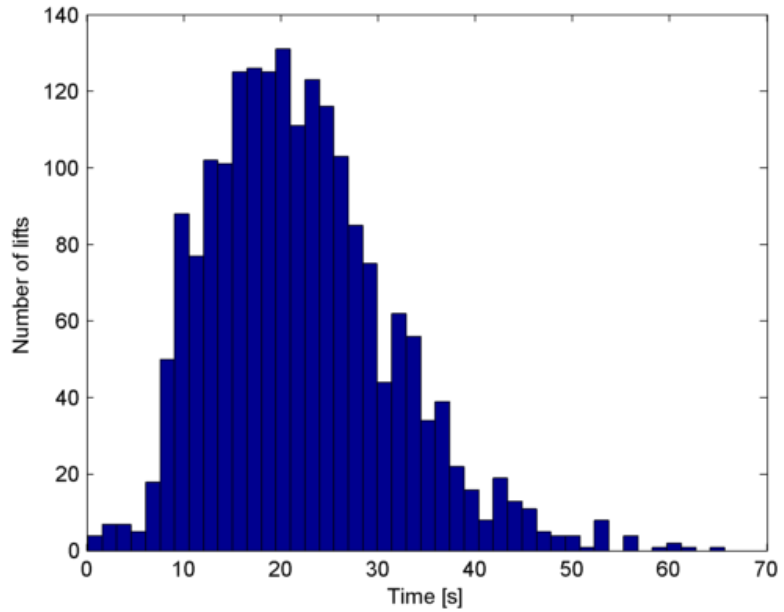

Figure 6: Histogram of the number of lifts with the measured duration, data collected over a period of 4 days

The speed at which the container is lifted depends on the weight of the containers, with lighter containers lifted at a vertical speed of 52 metres per minute, while at full load (40 tons) the speed is limited to 26 metres per minute (according to the manufacturing company (ZPMC) crane manual); this results in a slight increase of the duration of the lift when lifting containers of higher mass, as shown in Figure 7.

\subsection{Energy demand and crane activity}

The energy consumption of a crane is correlated to its level of activity, with the following relations: 


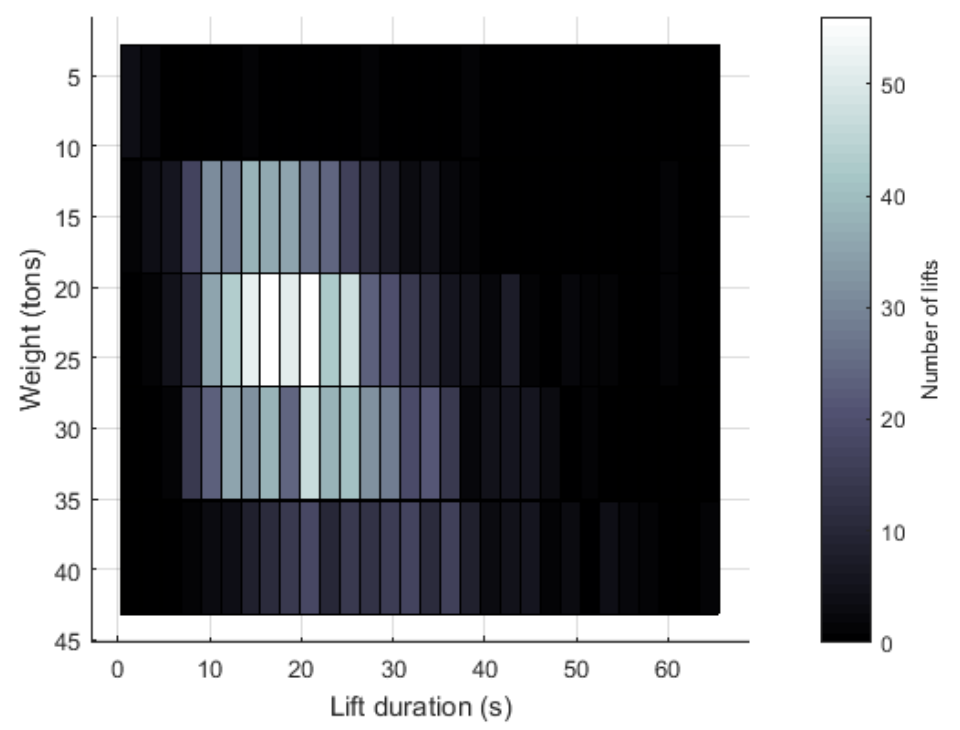

Figure 7: Distribution of lift durations. The brightness increases with the number of lift durations with the specified mass.

- The container weight is directly proportional to the energy required to lift a container. A distribution of weights that shows a greater amount of heavy containers will result in a higher energy consumption.

- Frequent container movements is linked to high energy consumption of the crane as the idle times are shorter. This is due to short intervals between lifts, so if this value is low the energy consumption is high.

- Ports with small terminal area and high tonnage are often characterised by high container stacks, which leads to high lift duration. By measuring the duration of the lifts it is possible to compare the energy consumptions of ports of equivalent tonnage, knowing that the power required by hoists motor is proportional to the average lift duration. The measured distribution of the lift durations can then help predict the energy consumption.

The statistical values presented in this section can be used to explain the differences in energy consumption between ports or between different timeframes in the same port. It will be later evident that the major factor in a 


\begin{tabular}{|c|c|c|c|}
\hline & $\begin{array}{l}\text { Container } \\
\text { weight }\end{array}$ & Intervals & Lift duration \\
\hline Maximum value & 32.3 tons & $298.5 \mathrm{~s}$ & $65.6 \mathrm{~s}$ \\
\hline Minimum value & 1.2 tons & $4.5 \mathrm{~s}$ & $1.0 \mathrm{~s}$ \\
\hline Mean value & 16.3 tons & $83.0 \mathrm{~s}$ & $22.1 \mathrm{~s}$ \\
\hline Median value & 15.3 tons & $58.0 \mathrm{~s}$ & $21.0 \mathrm{~s}$ \\
\hline
\end{tabular}

Table 2: Statistical information on container weight, duration of intervals between lifts and duration of lifts. Data collected over a period of 4 days.

typical port will be the number of container moved per unit of time, i.e. the interval between lifts.

\section{Time and energy distribution for an RTG crane}

The RTG crane has three modes of operation: working, idle and switched off. When the crane is working, it is actively performing a task such as lifting/lowering a container. The idle mode is a "waiting" mode when the crane is switched on but does not perform any task. Finally when the crane is switched off, the control enabling switches are off, the motors are turned off and the crane does not perform any task. The crane can be in idle mode when it is waiting for a truck or in the case that the crane operator is on a break. The states of the motors' speeds and the switches are shown in table 3 . When then crane is working, the speeds of the hoist, trolley and gantry motors are non-zero and the control enabling switches are turned on. In the case the crane is switched off the motors' speeds are zero, the switches are turned off and the DC bus voltage is under $570 \mathrm{~V}$. Finally when the crane is in idle mode the motors' speeds are zero but the switches are turned on.

\begin{tabular}{|l|l|l|l|}
\hline & Working & Idle & $\begin{array}{l}\text { Switched } \\
\text { off }\end{array}$ \\
\hline Hoist, trolley and gantry speeds & $6=0$ & 0 & 0 \\
\hline Control enabling switches & on & on & off \\
\hline DC bus Voltage & & & $<570 \mathrm{~V}$ \\
\hline
\end{tabular}

Table 3: Crane modes and their description

As seen in figure 8a on average an RTG crane at port of Felixstowe is working about $50 \%$ of the time while about $30 \%$ of the time the crane is in 
idle mode while waiting for a truck. During the idle period the rectifier is switched off to reduce standby energy consumption; therefore the energy passing through the rectifier is associated with the crane in active mode. The remaining time the crane remains switched off.

The energy that is measured at the input to the rectifier is then distributed between hoist and gantry while the remaining amount accounts for the losses, the energy consumed by the gantry and the energy in the idle mode. Figure $8 \mathrm{~b}$ shows that on a typical day about $60 \%$ of the energy is consumed on the hoist motor, $30 \%$ on the gantry motor and $7 \%$ on trolley, idle energy and losses.

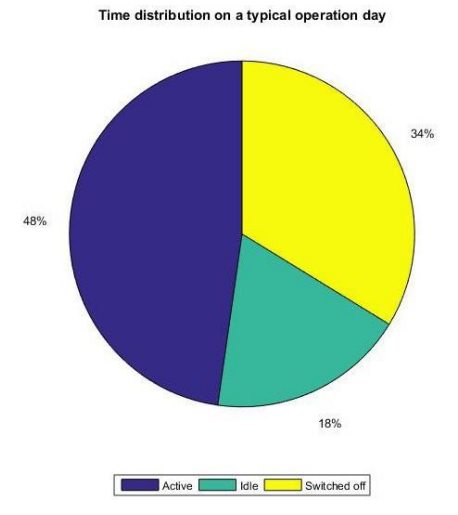

(a) Average time distribution

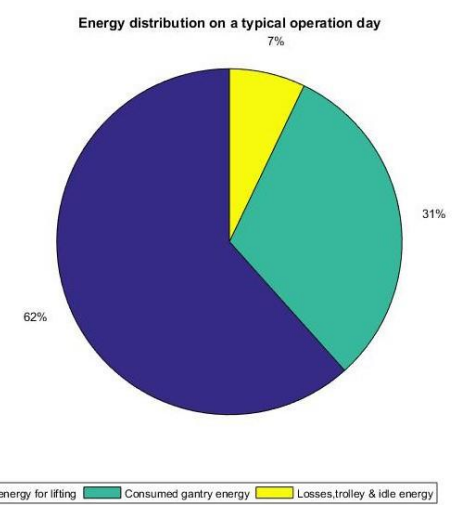

(b) Average energy distribution

Figure 8: Distribution of crane activity on a typical day of operation for an RTG crane in port of Felixstowe.

\section{Results}

In this section the results regarding the energy generated and consumed by the various motors of the crane are being presented.

\subsection{Rectifier energy}

The energy passing through the rectifier has been calculated by integrating the electric power measured at the input to the rectifier over time (Equation (1)). Figure 9 indicates that for typical operation days 1,2,3,4 the crane was active and working from 10.3 to 12.7 hours and the rectifier energy ranged from 711.2 to $822.7 \mathrm{kWh}$. For low activity days 4,5 the crane was active and working from 6.7 to 7.3 hours and the rectifier energy varied from 439.9 to $499.2 \mathrm{kWh}$. Finally, days 7 and 8 were very low activity days 
(Sunday and bank holiday) as the crane worked only for 1.4-2.1 hours and the rectifier energy was measured to be in the range of 112.8 to $160.8 \mathrm{kWh}$.

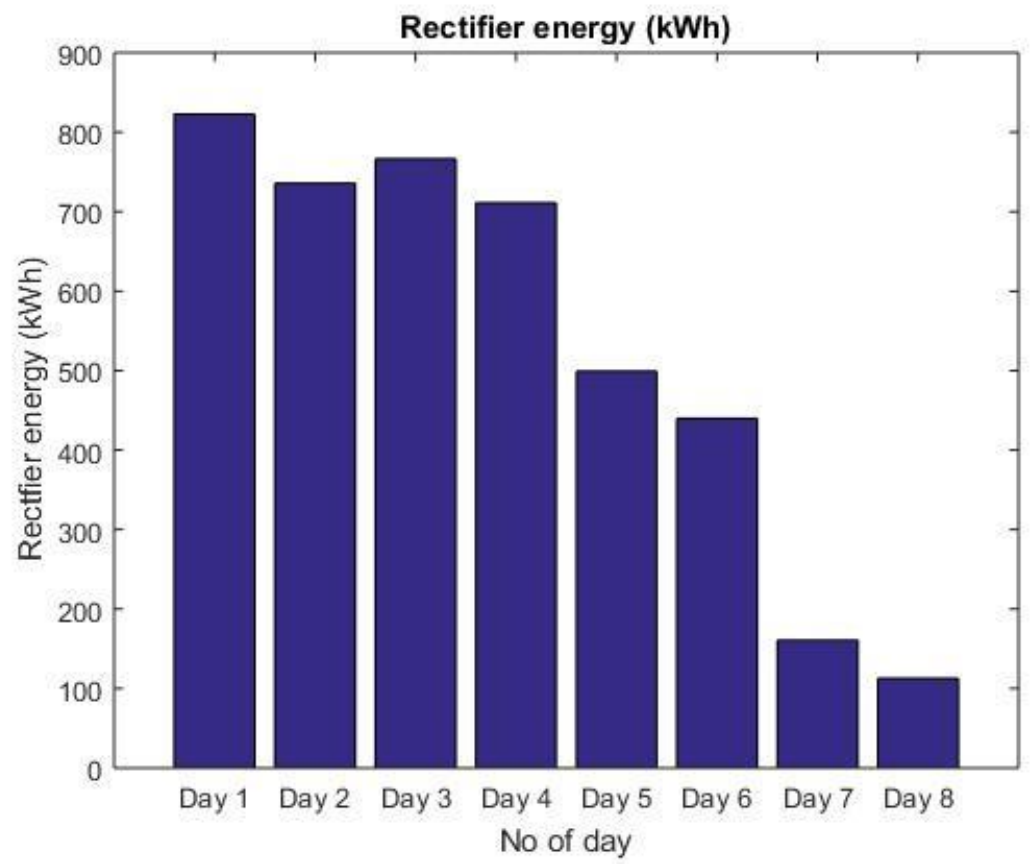

Figure 9: Rectifier energy in kWh for eight working days

\subsection{Hoist energy}

Measurements of AC voltage at the motor terminals were not available, therefore in order to calculate the hoist energy that is consumed during lifting and generated during a lowering operation, the hoist voltages had to be calculated based on the hoist speeds. Information obtained from the terminal operators indicate that the motor $\mathrm{AC}$ voltages depend on the speed (which has been measured). In the case of the hoist motor, the voltage linearly increases from $0 \mathrm{~V}$ to $415 \mathrm{~V}$ when the speed increases from $0 \%$ to $50 \%$ of the rated speed, then it remains approximately constant at $415 \mathrm{~V}$ for speeds between $50 \%$ and $100 \%$ of the rated speed.

Lifting and lowering energy have been calculated using formula 1. Lifting energy refers to the total amount of energy that was consumed for lifting (and the hoist speed is positive) while lowering energy indicates the total amount of energy that was generated when lowering a container (and the hoist speed is negative).In figure 10 the total hoist lifting energy ranges from 
413.4 to $517.5 \mathrm{kWh}$ while the total hoist lowering energy varies from 357.5 to $457.2 \mathrm{kWh}$ on a typical day. These numbers indicate that a significant amount of energy can potentially be recovered as the percentage of the potential hoist energy that can be recovered ranges from $83.8 \%$ to $89.02 \%$. In figure 11 the hoist energy has been separated for locked and unlocked spreader states. The different amounts of energy have been calculated while the crane is lifting/lowering the locked spreader plus a container and the unlocked spreader only.

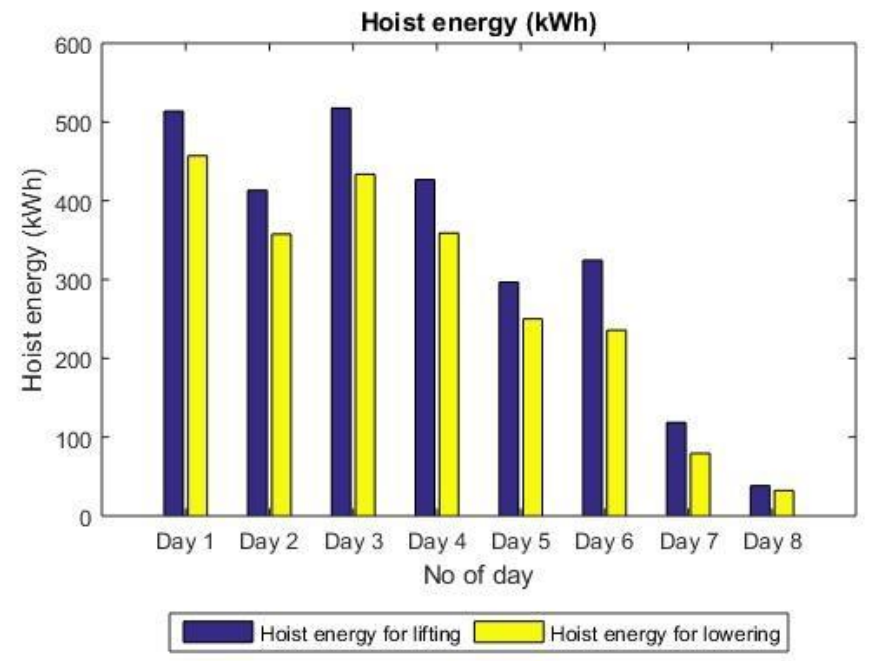

Figure 10: Consumed and recoverable hoist energy per day

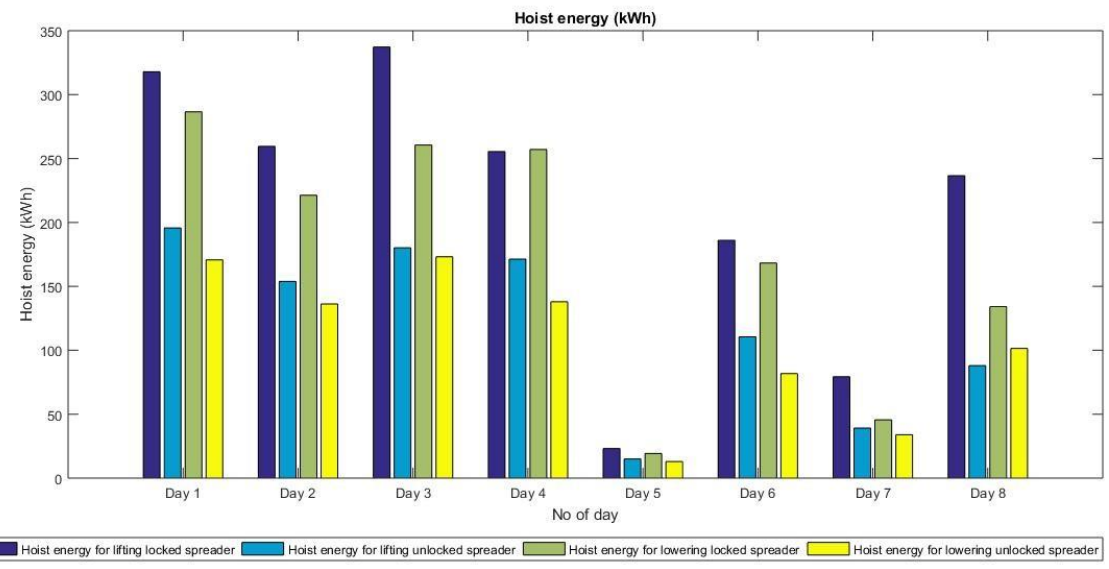


Figure 11: Consumed and recoverable hoist energy in kWh per day for locked and unlocked spreader

\subsection{Gantry energy}

The consumed gantry energy was calculated by integrating the gantry power over the time with at least one of the four gantry motors working. The potentially recoverable gantry energy is the regenerated energy that comes from the gantry motors when the voltage is higher than the brake resistors activation level $(750 \mathrm{~V})$. As seen in figure 12 , on a typical day the consumed gantry energy per day ranges from 192.7 to $273.4 \mathrm{kWh}$ while the potentially recoverable gantry energy ranges from 8.61 to $12.6 \mathrm{kWh}$. This indicates that a very small amount of gantry energy can be recovered and the percentage of potential recoverable gantry energy varies from $4.08 \%$ to $5.06 \%$ (table 4 ).

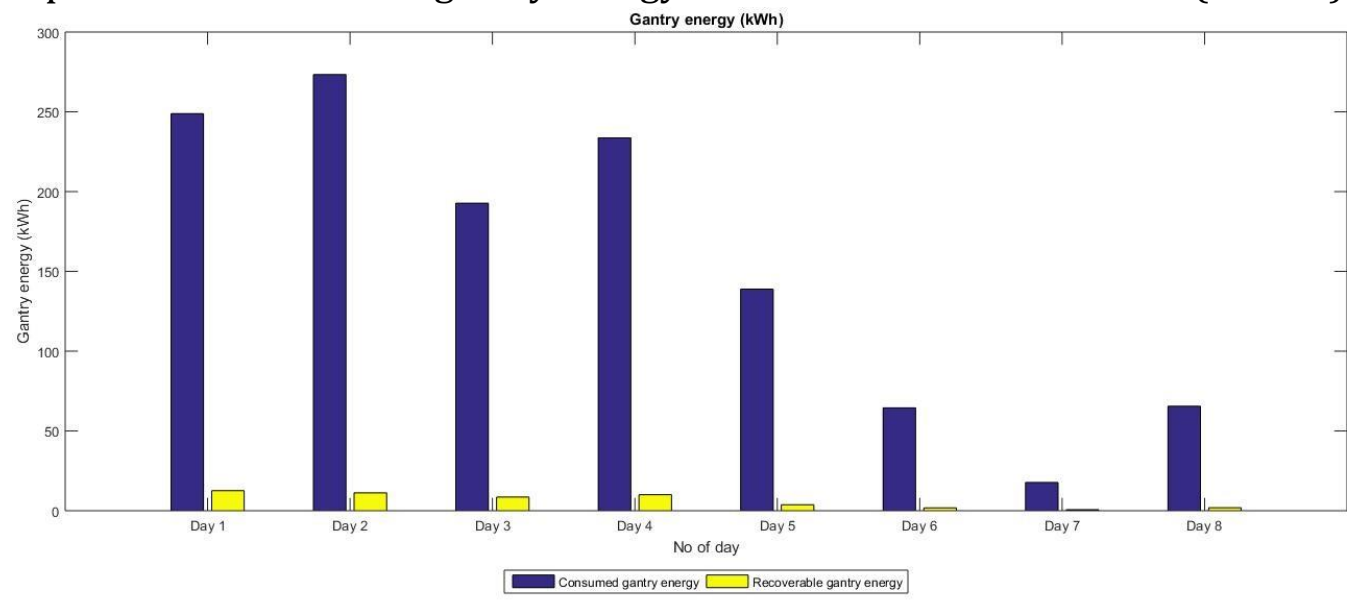

Figure 12: Consumed and recoverable gantry energy in kWh per day

\subsection{Losses}

The losses are mostly due to the friction between wires and sheaves and also in the hoist motor gearbox. Energy is also dissipated in the hoist induction motor and in the power converters. Unlike the energy normally dumped in the brake resistors, this lost energy cannot be recovered by means of an energy storage system. The lost energy accounts for not less than $7 \%$ of the total consumed energy. As measurements were taken in the AC side of 
the host motor there are not any other significant sources of losses, and especially not from other motors except for the hoist.

\begin{tabular}{|l|l|l|l|l|l|l|l|l|}
\hline & \multicolumn{4}{|c|}{ Typical } & \multicolumn{3}{c|}{ Low } & \multicolumn{2}{c|}{ Very low } \\
\hline No of test & 1 & 2 & 3 & 4 & 5 & 6 & 7 & 8 \\
\hline $\begin{array}{l}\text { Hoist } \\
\text { energy\% }\end{array}$ & 89.0 & 86.5 & 83.8 & 84.1 & 84.3 & 72.6 & 67.1 & 84.2 \\
\hline $\begin{array}{l}\text { Gantry } \\
\text { energy\% }\end{array}$ & 5.06 & 4.09 & 4.47 & 4.30 & 2.68 & 2.80 & 3.54 & 2.87 \\
\hline $\begin{array}{l}\text { Total } \\
\text { energy\% }\end{array}$ & 57.1 & 50.1 & 57.7 & 51.9 & 50.8 & 54.0 & 49.8 & 30.2 \\
\hline
\end{tabular}

Table 4: Percentage of recoverable energy

\subsection{Estimation of potentially recoverable energy}

The potential energy that can be recovered when lowering a container is a fraction of the electric energy required to lift the same container because of the presence of unavoidable friction and electric losses. The percentage of total recoverable energy, $E_{R}$, is given by equation 4 .

$$
E_{R}=\frac{E_{-}}{E_{+}} \times 100
$$

where $E_{\text {- }}$ is the recoverable energy for hoist and gantry operations, $E_{+}$is the total energy consumed by the hoist, gantry, trolley, and the energy losses. As seen in Table 4, the greatest amount of recoverable energy comes from the hoist. For a typical operation day $84 \%$ - $89 \%$ of the hoist energy can be recovered while for lower activity days $67 \%-84 \%$ can be recovered. The percentage of recoverable gantry energy is significantly smaller as it only ranges from $2.6 \%$ to $5 \%$. For a typical or low activity day the percentage of total recoverable energy varies between $50 \%$ and $57 \%$ while for very low activity days $30 \%-49 \%$ of the energy can be recovered (table 4 ).

\section{Discussion}

Although this analysis has been based on eight days of data, the results can be reflected in a whole operational year of a crane as the data corresponds to working days with different types of workload (normal, low 
activity, very low activity as seen in table 1). Thus, savings in energy, fuel, cost and $\mathrm{CO}_{2}$ emissions are estimated on an annual time frame.

According to the data, the typical RTG crane in Port of Felixstow is only active about $50 \%$ of the time and the remaining time it is either in idle mode waiting for a container or switched off (figure 8a). During its active time about $60 \%$ of the energy is used in raising containers by the hoist while $30 \%$ is used by the gantry motor (figure $8 \mathrm{~b}$ ). The remaining $10 \%$ accounts for the trolley, idle energy and losses. Regarding the potential recoverable energy, the greatest part comes from the hoist motor when it is lowering containers and thus acting as a generator. The average percentage of recoverable hoist energy roughly ranges from $70 \%$ to $80 \%$ (figure 10 ). The results show that very little energy can be recovered from the movement of the gantry motors as only $3 \%-5 \%$ of this energy has been calculated to be recoverable. The percentage of the total recoverable energy has been calculated to range from $50 \%$ to $57 \%$ on a typical operation day (table 4). The average total recoverable energy (including hoist and gantry recoverable energy) for a typical operation day is approximately $313 \mathrm{kWh}$. Since cranes in Port of Felixstow work 250 days a year according to the ports administration, the yearly amount of potential recoverable energy could reach to 78250 $\mathrm{kWh} / 78.25 \mathrm{MWh}$ if a storage system would be fitted.

Additionally, if this amount of energy could be recovered savings could be achieved in regards to fuel consumption and cost. According to information the port's technical stuff provided us with, the conversion efficiency of the diesel genset from diesel to $\mathrm{kWh}$ (e) is $25 \%$, so one litre of diesel fuel will produce 2.4-2.5 kg CO2 per kWh (e). So savings of $78.25 \mathrm{MWh}$ will result in fuel savings of 32,600 litres of fuel per year. With an average price of fuel of $£ 0.6$, this will result in an annual fuel saving of $£ 19,600$.

While the operator may only be interested in fuel savings, society will be interested in the environmental benefits that such system can bring. With each litre of diesel fuel that is consumed, $2.5 \mathrm{~kg} \mathrm{CO}_{2}$ emissions are associated; Hence savings of 32,600 litres will result in savings of 81 tonnes of $\mathrm{CO}_{2}$ per crane per year. Since Port of Felixstowe has a fleet of about 100 RTG cranes the total savings across the Port could be as high as 8,100 tonnes.

\section{Conclusions}

In this paper an analysis of the energy in usage for RTG cranes has been presented. Whether an RTG crane is diesel or electrically operated about half 
the energy consumed during normal operation is recoverable (table 4). The greatest part of the consumed and recovered energy, in the order of $300 \mathrm{kWh}$ per day, is due to the hoist motor. If the recovered energy is stored at point of use then it can be used to perform the lift of the next container or limit the peak demand. As a result the demand on the primary energy source is reduced and the overall efficiency of the system increases.

This applies equally to RTGs which are powered by diesel generators or the electric grid. As the price of energy increases the payback time of energy storage systems will decrease, and the selection of a suitable energy storage system will depend primarily on the efficiency and durability of the system. On average, each RTG moves a container every 83 seconds which translates to hundreds of thousands of lifts per year during a designed life of twenty years; this amounts to million lift cycles to match the life of the portal frame.

\section{Acknowledgements}

We would like to thank the engineering staff at port of Felixstowe for instrumenting and collecting data from the RTG crane. We also acknowledge the receipt of financial support from Climate KIC. 
[1] Brinkmann B., "Operations systems of container terminals A compendious overview," Handbook of Terminal Planning Operations Research, 2011

[2] Knight C., Becerra V. , Holderbaum W. , Mayer R., "A Simulink Model of an RTG Crane," TSBE Conference 2012, 2012.

[3] Knight C., Becerra V., Holderbaum W., Mayer R., "Development and deployment of a control system for energy storage," TSBE Conference 2013, 2013.

[4] Kim, Y.-S., Hong, K.-S., Sul, S.-K., "Anti-sway control of container cranes: Inclinometer, observer, and state feedback," International Journal of Control, Automation, and Systems, 2004

[5] Kim S., Sul S., "Control of rubber tyred gantry crane with energy storage based on supercapacitor," IEEE Trans. Power Electron, 2006.

[6] Pietrosanti S., Holderbaum W., Becerra V., "Modelling power flow in a hoist motor of a Rubber Tyred Gantry crane," IEEE Trans. Ind. Appl., vol. 52, no. 3, pp. 2088 - 2094, 2016.

[7] Mahlia T. M. I., Saktisahdan T. J., Jannifar A., Hasan M. H. , Matseelar H. S. C., "A review of available methods and development on energy storage; technology update," Renew. Sustain. Energy Rev., vol. 33, 2014.

[8] Jiakai X., Jiaqiang Y., and Jian G. , "An integrated kinetic energy recovery system for peak power transfer in 3-DOF mobile crane robot," Syst. Integr. (SII), 2011.

[9] Flynn, M.M., Mcmullen, P., Solis, O., "Saving energy using flywheels," IEEE Industry Application Magazine 14, 2008.

[10] Obata, K., Sakamoto, T., Yoshioka, N., Fujisawa, N., Yoshikawa, H., Monzen, T., "Grid-Powered Electric Transfer Crane," Mitsubishi Heavy Industries Technical Review, 2010.

[11] Liu W. L. W. ,Zhu Z. Z. Z.,Chang C. C. C. ,Wang R. W. R.,Xu H. X. H. , "Research of system of energy recycling on Rubber-Tyred Gantry crane," 2008 Int. Conf. Electr. Mach. Syst., pp. 21832187, 2008. 
[12] Flynn M.M, McMullen P., Solis O., "High-speed flywheel and motor drive operation for energy recovery in a mobile gantry crane," Conf. Proc. IEEE Appl. Power Electron. Conf. Expo. - APEC, pp. 11511157, 2007.

[13] Baalbergen F., Bauer P., Ferreira J. A. , "Energy Storage and Power Management for Typical 4Q-Load," IEEE Trans. Ind. Electron., vol. 56, no. 5, pp. 14851498, 2009.

[14] Musolino V., Pievatolo A.,Tironi E. "A statistical approach to electrical storage sizing with application to the recovery of braking energy," Energy, vol. 36, pp. 6697-6704, 2011.

[15] Rubber tired gantry (RTG) crane load factor study, Port of Long Beach and The port of Los Angeles http://www.polb.com/civica/ filebank/blobdload.asp?BlobID=6915/, 18042016

[16] Glover J. D., Sarma M. , Overbye T., "Power Systems Analysis and Design.” Cengage Learning, 2007.

[17] Yang Y.C., Chang W.M. , "Impacts of electric rubber-tired gantries on green port performance.", Res. Transp. Bus. Manag., vol. 8, no. 2013, pp. 6776, 2013.

[18] Baalbergen F.,Bauer P., Ferreira J.A, "Energy Storage and Power Management for Typical 4Q-Load." IEEE Trans. Ind. Electron., vol. 56, no. 5, pp. 14851498, 2009.

[19] Kamwa I., "Dynamic modelling and robust regulation of a no-storage wind-Diesel hybrid power system." Electric Power System Research, vol. 18, по. 3, pp. 219-230, 1990.

[20] Pietrosanti S., Holderbaum W., Becerra V., "Optimal Power Management Strategy for Energy Storage with Stochastic Loads," Energies, vol. 9, no. 3, p. 175, 2016.

[21] Niu W., Huang X., Yuan F., Schofield N., Xu L., Chu J., Gu W., "Sizing of Energy System of a Hybrid Lithium Battery RTG Crane," IEEE Trans. Power Electron., vol. 8993, no. c, pp. 11, 2016. 